\title{
Characteristics of inflammation common to both diabetes and periodontitis: are predictive diagnosis and targeted preventive measures possible?
}

\author{
Philip J. Hanes • Ranjitha Krishna
}

Received: 3 December 2009 / Accepted: 24 January 2010/Published online: 3 April 2010

(C) European Association for Predictive, Preventive and Personalised Medicine 2010

\begin{abstract}
Diabetes and periodontitis are chronic inflammatory disorders that contribute to each others' severity and worsen each others' prognosis. Studies have shown that patients with diabetes are at increased risk of developing periodontitis, and that diabetics with untreated periodontitis have more difficulty controlling serum glucose. Periodontal treatment that reduces gingival inflammation aids in the control of hyperglycemia. Periodontitis is accompanied by gingival bleeding and the production of an inflammatory exudate termed gingival crevicular fluid (GCF) that arises from the inflamed gingival tissues surrounding the teeth. GCF contains byproducts of connective tissue degradation, enzymes from host and bacterial cells, cytokines and other inflammatory mediators, and has been studied for screening blood glucose and for biomarkers of both diabetes and periodontitis. This review focuses on the inter-relationship between diabetes and periodontitis and the biomarkers common to both these diseases that may enable earlier detection, targeted preventive measures and individualized therapeutic intervention of these chronic conditions.
\end{abstract}

Keywords Periodontitis · Diabetes · Inflammation ·

Biomarkers · Gingival crevicular fluid .

Individualized treatment

\section{Introduction}

The identification and utilization of diagnostic biomarkers of various disease states has been advocated as a means of

P. J. Hanes $\cdot$ R. Krishna $(\triangle)$

Department of Periodontics,

Medical College of Georgia School of Dentistry,

Augusta, GA 30912, USA

e-mail: rkrishna@mail.mcg.edu simplifying or improving the accuracy and efficiency of diagnostic procedures. In 2001, an NIH working group standardized the definition of a biomarker as "a characteristic that is objectively measured and evaluated as an indicator of normal biological processes, pathogenic processes, or pharmacologic responses to a therapeutic intervention" [1]. Improved diagnostic efforts resulting from the utilization of novel biomarkers should enable optimal treatment planning and a more focused prevention of common human pathologies. Such biomarkers could also be used to screen healthy patients and identify those who may be predisposed to potential pathologies later in life and thereby enable the clinician to implement well-timed preventive measures. For the last two decades efforts have been made to identify biomarkers for diabetes mellitus and periodontitis. Diabetes and periodontitis are chronic inflammatory diseases which share a number of pathogenic mechanisms with common inflammatory mediators which have been investigated as possible biomarkers of disease status. This review describes the relationship between diabetes mellitus and periodontitis and summarizes the research aimed at the identification of biomarkers for these two diseases.

Diabetes mellitus (DM) is a group of disorders associated with a quantitative reduction in insulin production or a qualitative reduction in the action of insulin leading to changes in carbohydrate, protein, and lipid metabolism [2] and accumulation of glucose in the bloodstream. Increased glucose in the bloodstream results in hyperglycemia which affects a variety of tissues and organ systems including eyes, nerves, kidneys, and blood vessels. The periodontal tissues are also affected as a result of hyperglycemia, and periodontitis has been described as the sixth complication of diabetes mellitus [3].

The public health burden of diabetes in the world is enormous and many of the people suffering from diabetes 
are unaware of the problem. The most common types of diabetes include type 1 , type 2 , and gestational diabetes, although some other forms also exist. Type $1 \mathrm{DM}$ is caused by the destruction of $\beta$-cells in the pancreatic islets of Langerhans [4] and most often occurs in children and young adults. Type 2 DM usually occurs in adults, but may also been seen in children and young adults and is the more common form of DM. This is also the form of DM that is most commonly encountered in the dental office. Type 2 $\mathrm{DM}$ is a chronic condition and unlike type $1 \mathrm{DM}$, can remain undiagnosed for a long time and may in fact be first recognized by a dental care provider. Type $2 \mathrm{DM}$ is characterized by increased glucose production in the liver and increased peripheral resistance to insulin in the muscles and a subsequent reduction in insulin secretion. Exercise and weight loss improve insulin sensitivity in these patients and decrease insulin sensitivity in the peripheral tissues. Medications are often used to improve carbohydrate metabolism, increase pancreatic insulin production, or decrease insulin resistance. Sometimes, insulin is administered to improve glycemic state in type $2 \mathrm{DM}$ as well. Gestational diabetes occurs mostly in women in their third trimester of pregnancy and results in significant perinatal morbidity and mortality. Most patients with gestational diabetes return to their normal glycemic state after delivery although these women have been shown to be more likely to develop diabetes at a later age.

The major systemic complications and the resulting morbidity and mortality associated with diabetes has been attributed to a sustained state of hyperglycemia in the diabetic subject which leads to micro- and macrovascular complications and eventual damage to the structure and function within several major organ systems. In the large blood vessels, diabetes is associated with an increase in lipid deposition, thickening of arterial walls, and atheroma formation. Microvascular complications are due to damage of endothelial cells and alterations in endothelial basement membranes [2].

Diabetes has several effects on the oral cavity including xerostomia (reduced salivary flow), burning mouth, altered wound healing, and increased incidence of periodontal diseases such as gingivitis and periodontitis. Clinical studies have established that periodontal diseases are more prevalent and of greater severity in patients with type 1 or type 2 diabetes than in non-diabetic patients [5-9]. In addition, the prevalence and severity of gingival inflammation and bleeding within diabetic patients has been shown to be directly related to their level of metabolic control [10-15]. In fact, a strong positive association has been demonstrated between elevated HbA1c levels over a 2-year, pre-examination period and the presence and severity of periodontitis [16], and several studies have suggested a dose-response relationship between poor metabolic control and the severity of periodontitis [17-19]. In addition periodontal pockets with probing attachment loss occur more frequently in diabetics [20]; diabetics with more advanced systemic complications have more severe periodontitis [21]; and poorly controlled diabetics respond less favorably to periodontal treatment [22].

\section{The normal human periodontium}

The tissues that anchor the teeth and support them during health and function constitute the periodontium (Greek peri, "around"; odont, "tooth") and include the gingiva (Fig. 1), which covers the maxillary and mandibular alveolar bone, and the periodontal attachment apparatus (Fig. 2) which attaches the tooth to the jaw and includes cementum, periodontal ligament, and alveolar bone [23] (Fig. 3). In the normal periodontium, the gingiva surrounds the neck of each tooth, much like a collar. There is normally a shallow 2 to $3 \mathrm{~mm}$ space formed between the margin of the gingiva and the crown of the tooth where the gingiva overlaps a portion of the crown of the tooth [23]. This space between the crown of the tooth and the gingival tissue is the gingival sulcus (Fig. 4).

The periodontal attachment apparatus is the means by which the tooth is attached to the jaw and consists of the cementum on the root of the tooth, the alveolar bone lining
Fig. 1 Teeth surrounded by healthy periodontium

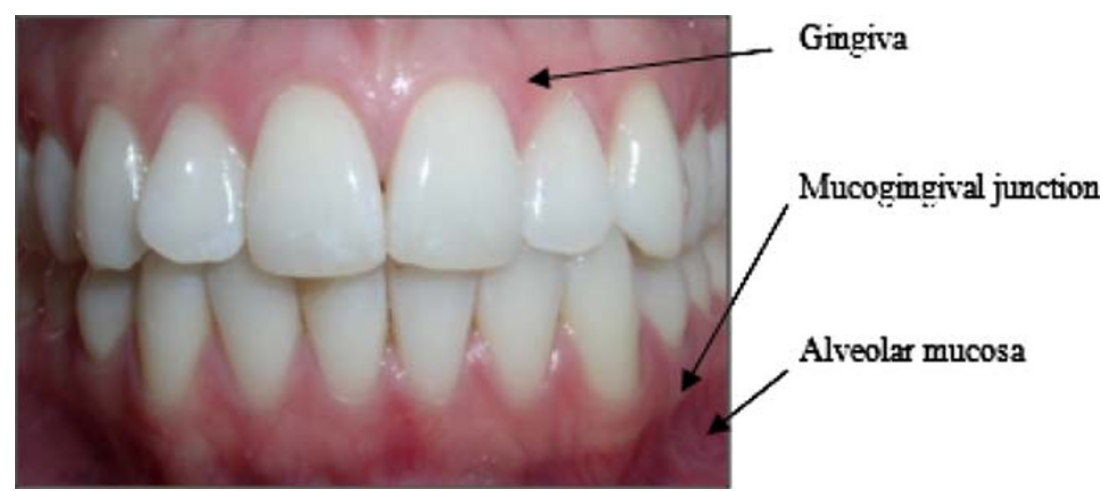




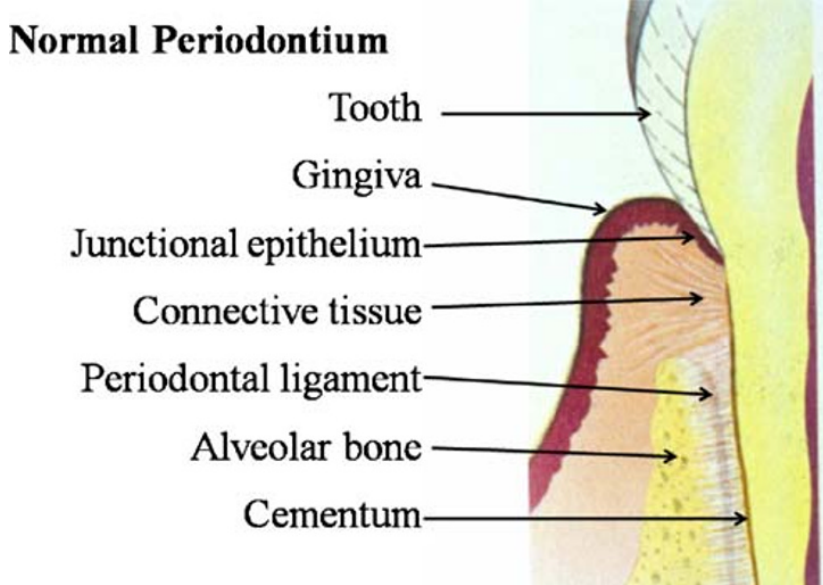

Fig. 2 Diagrammatic representation of the different components of the normal periodontium

the tooth socket and the periodontal ligament (Figs. 2 and 3). Cementum is a mineralized connective tissue that covers the roots of the teeth and its main function is to attach the periodontal ligament fibers to the teeth. It is similar in structure to bone, but differs from it in its microscopic organization, lack of vascularity, and the absence of continuous remodeling. The periodontal ligament is a dense, fibrous connective tissue that attaches the cementum of the tooth to the alveolar bone. It occupies a narrow $0.1-0.25 \mathrm{~mm}$ [24] space between two calcified structures, cementum and alveolar bone and is mainly made up of collagen fibers (Type 1 and 3), vascular elements, cells, and neural elements.

\section{Periodontal disease}

Diseases of the periodontium can be broadly classified as either gingivitis or periodontitis. Gingivitis is an inflamma-

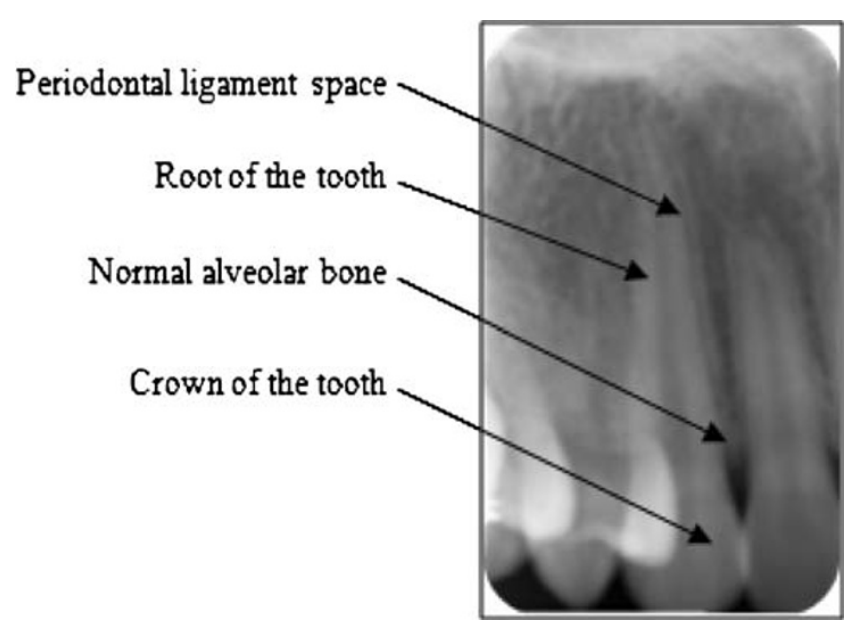

Fig. 3 Radiograph of healthy teeth and periodontium

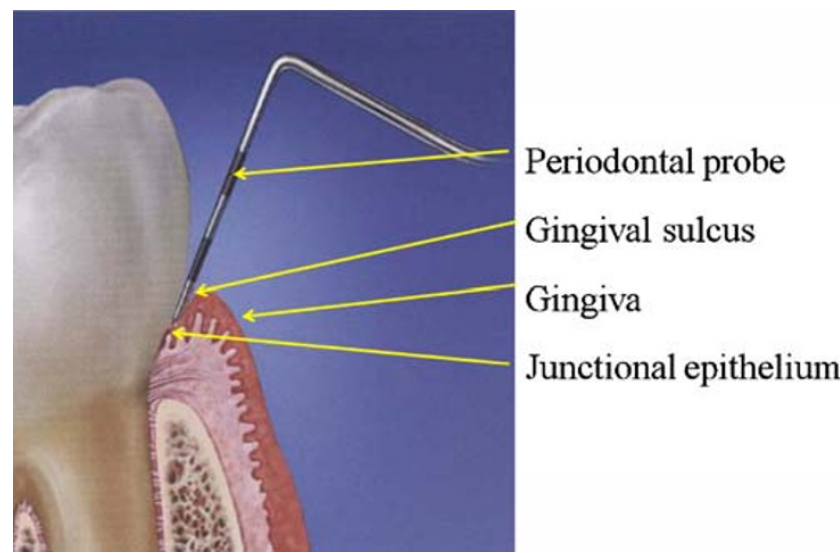

Fig. 4 Gingival sulcus

tion of the gingiva which manifests clinically with the usual signs and symptoms of inflammation including an increase in redness, swelling, bleeding, suppuration, and possible pain. Deposits of dental plaque and calculus are often found adherent to the tooth surface and in close contact with the gingival margin. The primary etiology of virtually all periodontal diseases is the bacterial biofilm termed dental plaque that forms on tooth surfaces. Periodontal infections are caused by anaerobic, gram-negative bacteria including Aggregatibacter actinomycetemcomitans, Tannerella forsythensis, Porphyromonas gingivalis, Prevotella intermedia, Fusobacterium nucleatum, Campylobacter rectus, and Treponema denticola. Although the primary etiology of periodontal diseases is the bacterial biofilm that is present on the surfaces of the teeth, these diseases are a result of a complex interplay between the bacterial products and the host response that are modified by behavioral and/or systemic factors [25]. About $50 \%$ of the tissue destruction associated with periodontal disease is attributed to host response. The immune response that develops in response to the chronic presence of plaque bacteria results in destruction of structural components of the periodontium, leading ultimately, to the clinical signs of periodontitis. Page and Schroeder [26] described the histopathogenesis of the lesion of gingivitis in three stages: initial ( $2-4$ days after bacterial insult), early (4-7 days after) and established (14-21 days after). The initial lesion is an acute vasculitis characterized by vascular changes consisting essentially of dilation of capillaries and increased vascular permeability with an infiltration of polymorphonuclear leukocytes (PMNs) in the space between the gingival margin and the tooth, in the epithelium lining this space and in the subjacent connective tissue. As the inflammatory lesion progresses to the next stage, clinical signs of erythema may appear due to the proliferation of capillaries and increased formation of capillary loops. The epithelium lining the space between the tooth and the gingival margin begins to proliferate into the subjacent infiltrated connective tissue, and the inflammatory infiltrate 
consists largely of lymphocytes and PMNs. Further alterations in the histopathology of the lesion associated with established gingivitis are consistent with the development of a chronic inflammatory lesion, with the appearance of numerous plasma cells, increased size of the inflammatory infiltration of the connective tissue and increased vascular changes wherein gingival blood vessels become engorged and congested. The established lesion can be observed clinically as moderate to severely inflamed gingiva (Fig. 5). If left untreated, the established lesion progresses to a fourth stage, which is the advanced lesion in which destruction of connective tissue attachment to the tooth and loss of supporting bone occurs.

Gingivitis is a common disease of the oral cavity. In the third National Health and Nutrition Examination Survey (NHANES III, 1988-94), 50\% of the US adult population was shown to have gingivitis on at least 4 teeth [27]. Although gingivitis is a fairly common disease and gingivitis is a pre-requisite for periodontitis, not all sites with gingivitis progress to periodontitis [28-31]. There are several factors other than the amount of plaque accumulation that have been shown to play a role in the progression of gingivitis to periodontal disease. These include but are not limited to age, pronounced inflammatory response, more pathogenic bacteria, stress, genetic predisposition (IL-1 positive genotype individuals), and smoking status [32-34].

Periodontitis is an inflammatory disease of the gingiva and the deeper periodontal tissues. Although periodontitis is preceded and accompanied by gingivitis, gingivitis may persist for indefinite periods without progressing to periodontitis. Periodontitis involves destruction of gingival and periodontal connective tissue fibers, resorption of toothsupporting bone, and apical proliferation of the junctional epithelium resulting in the formation of deep pockets between the gingiva and the tooth surface. These pockets harbor pathogenic periodontal bacteria which are the primary etiology of the periodontal lesion. If left untreated this inflammatory lesion progresses, eventually leading to loss of supporting structures of the teeth to the point that the tooth is lost.

Clinically, patients with periodontitis demonstrate all or some of the classical signs of inflammation seen in gingivitis along with pocket formation and radiographic bone loss (Fig. 6a and b). It is well documented that moderate periodontal disease affects a majority of the adult population, and is more severe in populations which do not receive regular dental care $[35,36]$.

The histopathologic lesion of periodontitis is characterized by apical proliferation of junctional epithelium onto cementum, lysis of collagen fibers of the periodontal ligament, and bone destruction at the alveolar crest (Fig. 7). There is an increase in the volume of the connective tissue inflammatory infiltrate characterized by the presence of PMNs, lymphocytes, macrophages, and plasma cells [26].

\section{The interrelationship between periodontal disease and diabetes}

Epidemiologic studies have shown a three- to four-fold increased risk for progressive periodontal destruction in diabetic patients compared with individuals without diabetes [37]. Although the biological basis for the relationship between periodontitis prevalence and severity and the level of metabolic control of diabetes has not been clearly elucidated [46], there is ample clinical evidence to support the view that poor glycemic control increases the risk in the diabetic patient for more severe periodontal disease with greater periodontal attachment loss, bone loss and deeper periodontal probing depths [38-44] (Fig. 8).

Early research into the relationship between diabetes and increased risk for periodontitis focused on potential differences in the bacterial microflora in diabetics versus nondiabetics. The majority of this research shows, however that the subgingival microbiota is very similar in diabetics and non-diabetics with periodontal disease $[45,46]$. Subsequent research has been focused on differences in the immunoinflammatory response to periodontal pathogens in diabetic versus non-diabetic subjects.

Multiple factors have been suggested to explain the relationship between diabetes mellitus and periodontal diseases including 1) altered immunoinflammatory response to bacterial pathogens, 2) diminution of the formative aspects of connective tissue metabolism, 3) impaired wound healing,
Fig. 5 Clinical presentation of gingivitis. Inflammation is localized to the gingiva and has not spread to the bone

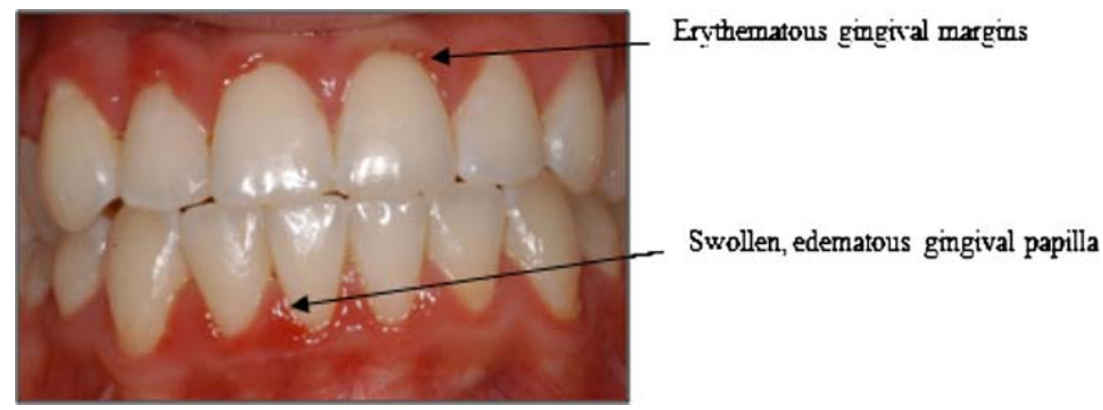


Fig. 6 a. Clinical appearance of periodontitis. Note gingival inflammation, heavy deposit of dental plaque and calculus and gingival recession. b. The radiograph from the same patient shows advanced bone loss and radiographic appearance of calculus deposits
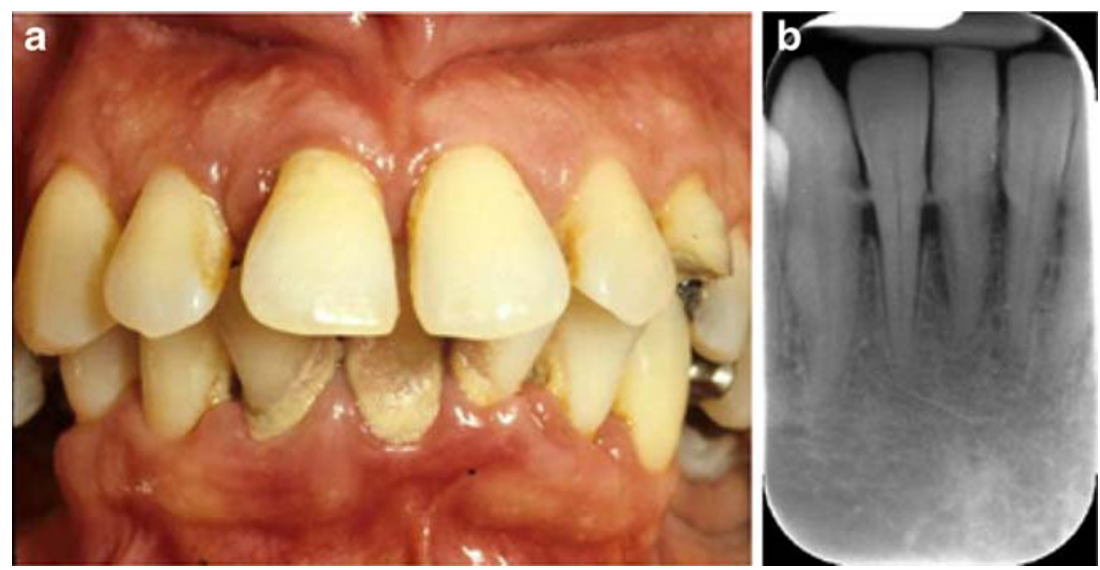

4) microvascular changes and 5) formation of advanced glycation end products [4]. Although the components of the bacterial biofilm are similar in comparisons of dental plaque samples from diabetic and non-diabetic patients [45-47], the immuno-inflammatory responses to these bacterial pathogens are altered in the diabetic patient. Immune cell functions such as adherence, chemotaxis and phagocytosis have been shown to be impaired in neutrophils from diabetic patients $[48,49]$. In addition the monocyte / macrophage cell line has been shown to be hyper-responsive to bacterial antigens, particularly during episodes of hyperglycemia, resulting in increased production of the proinflammatory cytokines IL- $1 \beta$ and TNF- $\alpha[50,51]$.

In addition to these altered immuno-inflammatory responses, the formative aspects of connective tissue metabolism appear to be diminished in the diabetic patient and to be related to the level of metabolic control. Bone turnover and osseous healing have been shown to be impaired under the influence of hyperglycemia [52-55] due to inhibition of osteoblastic cell proliferation and collagen production [56-58]. In addition, studies have shown an

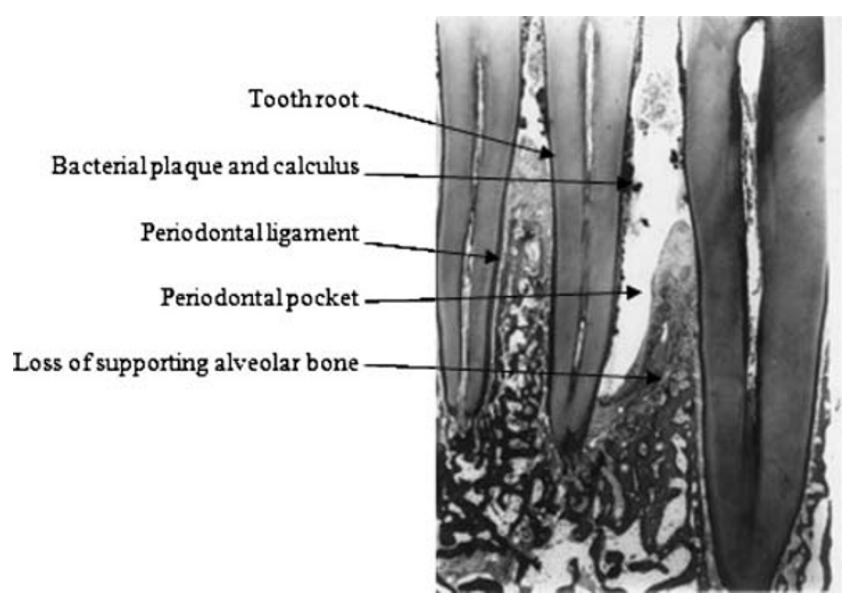

Fig. 7 Histology of periodontitis lesion. Bacterial-induced inflammation has resulted in loss of connective tissue attachment to the tooth, epithelial migration, pocket formation and loss of supporting bone increased apoptotic response of fibroblasts and osteoblasts to $P$. gingivalis infection in the presence of hyperglycemia, resulting in a net decrease in the numbers of these matrixproducing cells [59-61].

In addition to these inadequacies in the formative aspects of connective tissue metabolism, hyperglycemia-induced inhibition of the attachment and spreading of fibroblasts [62] and microvascular changes [12, 13] all contribute to impaired wound healing which is a common problem in the diabetic patient. Characteristic microvascular changes associated with diabetic complications, such as abnormal growth and regeneration of blood vessels, have also been described in the periodontal tissues [12-14]. Advanced glycation end products (AGEs) have been shown to accumulate in periodontal tissues in diabetic subjects [63] and to play a role in these microvascular alterations. AGEs bind irreversibly to collagen forming macromolecules which
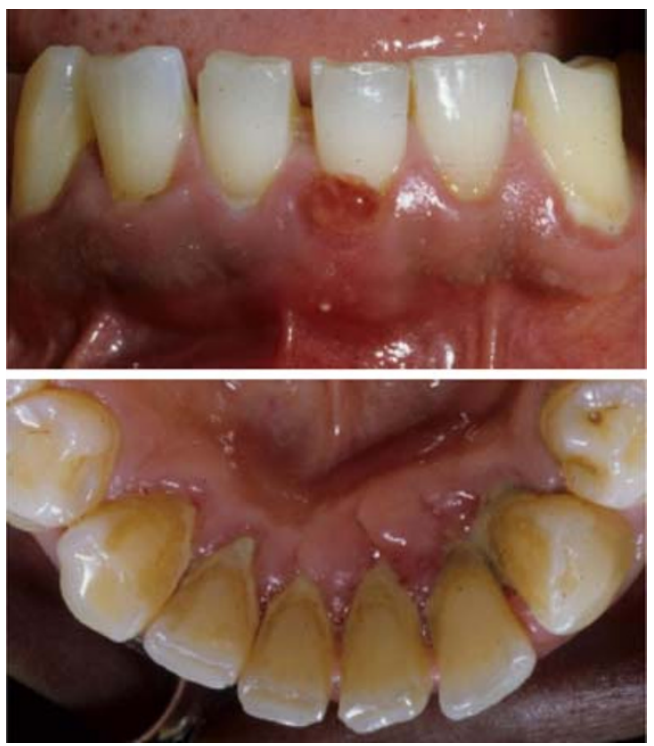

Fig. 8 Clinical presentation of periodontitis in patient with undiagnosed diabetes mellitus (type 1). History of multiple recurring periodontal abscesses 
accumulate in the basement membranes of endothelial cells resulting in increased basement membrane thickness and alteration in the normal homeostatic transport across the membrane [42]. AGE production has also been associated with increased production of vascular endothelial growth factor (VEGF), a cytokine that is also involved in the microvascular complications of diabetes $[64,65]$ and which has been reported to be elevated in the gingival tissues of diabetic patients [66].

The current knowledge about the relationship between diabetes and periodontal diseases suggests a bidirectional relationship between the two. Both diabetes mellitus and periodontitis can be classified as chronic inflammatory diseases although of different etiologic origin. Poorly controlled diabetic subjects tend to present with more severe periodontitis [67-70], and diabetic subjects with untreated periodontitis generally have poorer metabolic control of their diabetes [70-72]. Such studies suggest that severe, long-standing inflammatory lesions in the untreated patient with periodontitis could contribute to the exacerbation of diabetes. In contrast, several studies have reported a positive association between periodontal treatment and improved metabolic control of diabetes mellitus [73-76].

Studies have suggested that an abnormal inflammatory response known as a "hyper-inflammatory trait" occurs in subjects with diabetes [77, 78]. This hyper-inflammatory trait is characterized by an exaggerated secretion of inflammatory mediators such as TNF $\alpha$ and IL- 6 as well as systemic markers of inflammation. Over time hyperglycemia in the diabetic patient leads to glycation of structural proteins and lipids in the extracellular matrix and connective tissues as well as the vascular tissues [79-81]. These vascular changes lead to disturbances in capillary function, impaired perfusion of tissues and the release of reactive oxygen species resulting in a systemic inflammatory challenge $[82,83]$. In addition monocytes and endothelial cells can interact with advanced glycation end products (AGEs) via monocytic receptors (RAGE) to "prime" neutrophils and macrophages resulting in increased secretion of cytokines and inflammatory mediators by these cells. AGEs and elevated unsaturated fatty acids which are often associated with diabetes, are both capable of inducing a hypersecretory monocytic state leading to an increased production of inflammatory cytokines in response to antigenic or bacterial stimulus [84-87]. Both periodontitis and diabetes mellitus result in a systemic inflammatory challenge associated with a chronic elevation of inflammatory mediators including IL-1, TNF $\alpha$, IL-6, $\mathrm{PGE}_{2}$, C-reactive protein, and fibrinogen $[83,88,89]$. This hyper-inflammatory trait and the AGERAGE upregulation of the inflammatory response to bacterial antigens in the diabetic patient may result in a more severe systemic inflammatory challenge and overexpression of inflammatory mediators.
Given the fact that periodontal infections are associated with a predominately gram negative bacterial etiology, cytokines may also be secreted by cells in response to stimulation by bacterial lipopolysaccharide. In this case cytokine production occurs via a Toll-like receptor mediated response resulting in secretion of cytokines IL- $1 \beta$, IL- 6 , TNF$\alpha$, and $\mathrm{PGE}_{2}$, all of which are implicated in the tissue destruction associated with periodontitis [90, 91]. Infections such as periodontitis result in elevated levels of circulating cytokines including IL-1, TNF $\alpha$, and IL-6. These cytokines block lipoprotein lipase activity and induce hyperlipemia [83, 92, 93]. TNF $\alpha$ promotes glycogenolysis and impairs glucose uptake by cells leading to hyperglycemia [83, 93]. TNF $\alpha$ and IL- 6 also target the hepatocyte and lead to production of C-reactive protein [83, 92, 93]. The systemic inflammatory challenge associated with both diabetes mellitus and periodontitis link diabetic metabolic dysregulation and the severity of periodontal disease and shed light upon the interactions between chronic oral and systemic inflammatory diseases.

\section{Potential diagnostic components of gingival crevicular fluid}

As previously stated, both diabetes mellitus and periodontitis are chronic inflammatory diseases. As such, the markers of inflammation that are common to diabetes and periodontitis are an indication of disease control [94]. The initiation and progression of an inflammatory lesion in the periodontal tissues is positively associated with the flow of gingival crevicular fluid (GCF) from the gingival sulcus or periodontal pocket $[95,96]$ (Fig. 9). GCF is a serum exudate that originates in the microcirculation of the gingival tissues and flows into the gingival sulcus or periodontal pocket carrying with it mediators of local tissue destruction and byproducts of tissue metabolism [97]. Since the 1980s numerous studies have attempted to identify

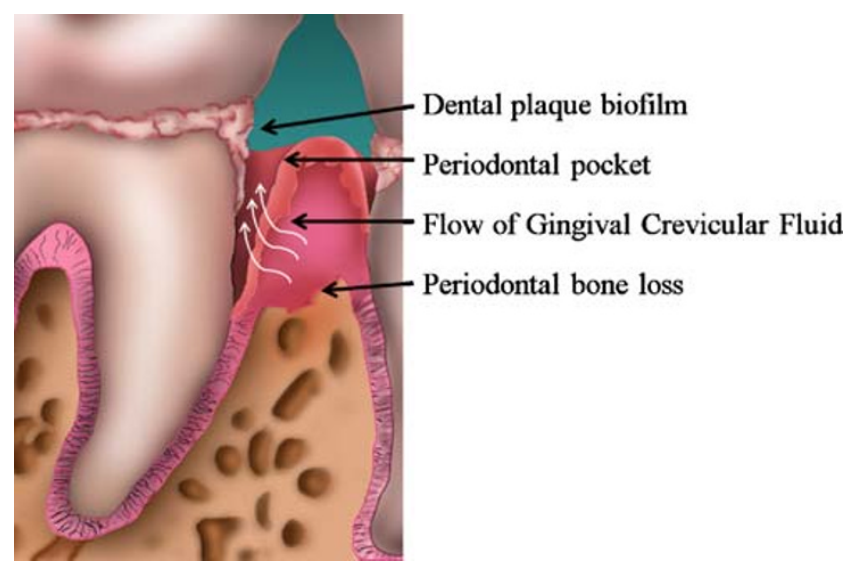

Fig. 9 Gingival crevicular fluid flow in a periodontal pocket 
components in the GCF which could aid in the identification of specific periodontally involved sites which are in active stages of tissue destruction [98], or to identify GCF components which could be used to screen patients for periodontitis or otherwise simplify periodontal examination and diagnosis [99-102]. The composition of GCF somewhat mirrors that of plasma [99] and has, therefore been of interest to clinicians as a less invasive medium to evaluate for various systemic conditions including diabetes.

\section{Glucose in GCF}

Efforts to evaluate glucose levels in samples of blood from the gingival sulcus or periodontal pocket during dental examinations have been advocated as a method of expanding the range of venues for diabetic screening due to the fact that this method does not require a "finger stick" and takes advantage of the presence of a blood sample that would otherwise be discarded in the dental office [103]. Gingival bleeding is a common, virtually ubiquitous symptom of gingivitis and periodontitis -a finding supported by the high frequency of dental patients who report that their gingival tissues routinely bleed when they brush and/or floss their teeth. Likewise the gingival tissues of these patients bleed during the gentle provocation of the tissues associated with a routine dental and periodontal examination. Several studies have shown that in diabetic subjects glucose levels in capillary blood obtained from "finger sticks" correlate with glucose levels from blood obtained from gingival sulci or periodontal pockets during routine periodontal examinations [104-112]. Although early studies reported moderate to good correlations between the glucose levels in gingival crevice blood and capillary blood, the length of time required for collection of samples and the need for special equipment and supplies for sample collection and analysis made the use of gingival blood samples cumbersome and inconvenient [104-106]. Parker et al. 1993 [113] tested the use of commercially available reagent strips and an in-home glucose monitoring device for the purpose of measuring glucose levels in gingival crevicular blood and found that $92 \%$ of glucose levels from gingival crevice blood samples were within acceptable levels of measurement error compared to $90 \%$ from capillary blood samples. More recent studies comparing the glucose levels from gingival crevice blood and capillary blood from finger sticks using in-home glucose monitoring devices have reported high intra-patient correlations using the Bayer Elite $2000(r=0.98 ; p<0.0001)$ [108], and the Xitux Diagnostics Smart-X self-monitoring blood glucose device $(r=0.997 ; p<0.0001)$ [107]. Contradictory findings were reported in a test of the Freestyle ${ }^{\circledR}$ Blood Glucose Monitoring System wherein agreement between measures of glucose level in gingival crevice and capillary blood samples was low when the data was compared using statistical measures of agreement/disagreement instead of correlation/regression $[109,110]$. Although it is possible that part of the discrepancy in the literature over the validity of glucose measurements in gingival crevice blood may be due to the smaller volume of blood sampled from the gingival crevice, studies have shown that glucose levels can be reliably determined in sub-microliter volumes $(0.2$ to 0.8 microliter) of GCF and that GCF glucose levels are significantly higher in periodontitis sites [114]. However, no effort was made in this study to correlate or to determine the level of agreement between measures of glucose levels from GCF and serum glucose levels [114]. In a more recent study Strauss et al. 2009 measured glucose levels from gingival crevice and capillary finger-stick blood in an OneTouch UltraMini Blood Glucose Monitoring System and compared these measurements using both measures of correlation and limits of agreement [103]. Samples were taken from patients with established gingivitis and bleeding on probing and compared with samples from patients with minimal inflammation and little or no bleeding. In the presence of frank gingivitis glucose levels in gingival crevice and capillary blood were highly correlated $(r=0.89)$ and the limits of agreement were acceptable ( -27.1 to 29.7$)$. On the other hand in the absence of gingivitis correlations between the measures of glucose level were lower $(0.78)$ and the limits of agreement were much wider $(-25.1$ to 80.5$)$. The authors concluded that in the absence of frank gingivitis it was difficult to obtain enough blood from the gingival crevice for measurements without touching the tooth as the tissues were manipulated to stimulate bleeding, possibly resulting in contamination of the sample. Taken together these studies suggest that samples of gingival crevice blood taken during an initial, pre-treatment dental examination may be used to screen previously undiagnosed patients for diabetes using commercially available glucose monitoring devices. However following dental and periodontal treatment when gingivitis and bleeding on probing have been successfully controlled, it will be difficult to obtain a sufficient volume of gingival crevice blood for reliable assessment of glucose levels.

Structural proteins and proteolytic enzymes

The identification of biomarkers of periodontal disease presence or active disease status has been a somewhat elusive goal in periodontal research. Considerable effort has been expended on the identification of some component of the GCF which could identify a site or a patient at risk or predict an impending episode of disease progression. Research efforts have focused on the presence of tissue specific structural molecules including collagen fragments such as type 1 collagen carboxyterminal telopeptide, proteoglycans such as chondroitin sulfate, hyaluronan, heparin 


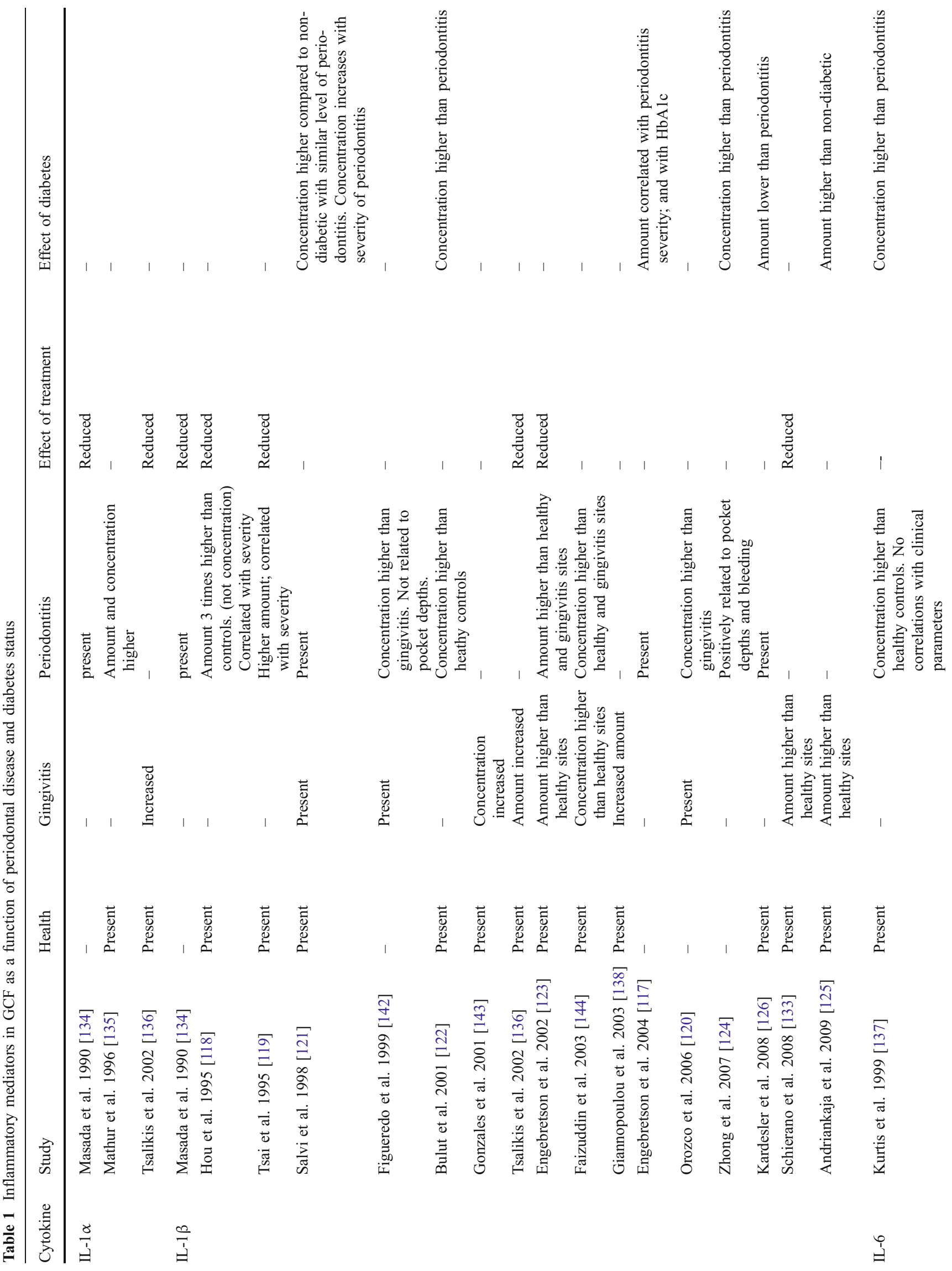




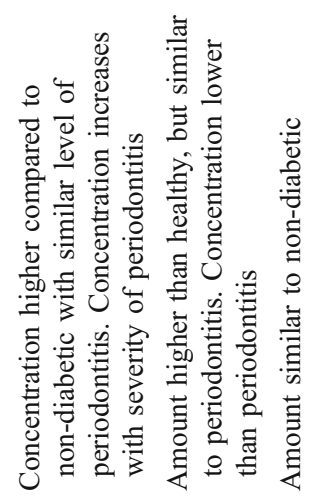

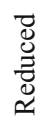
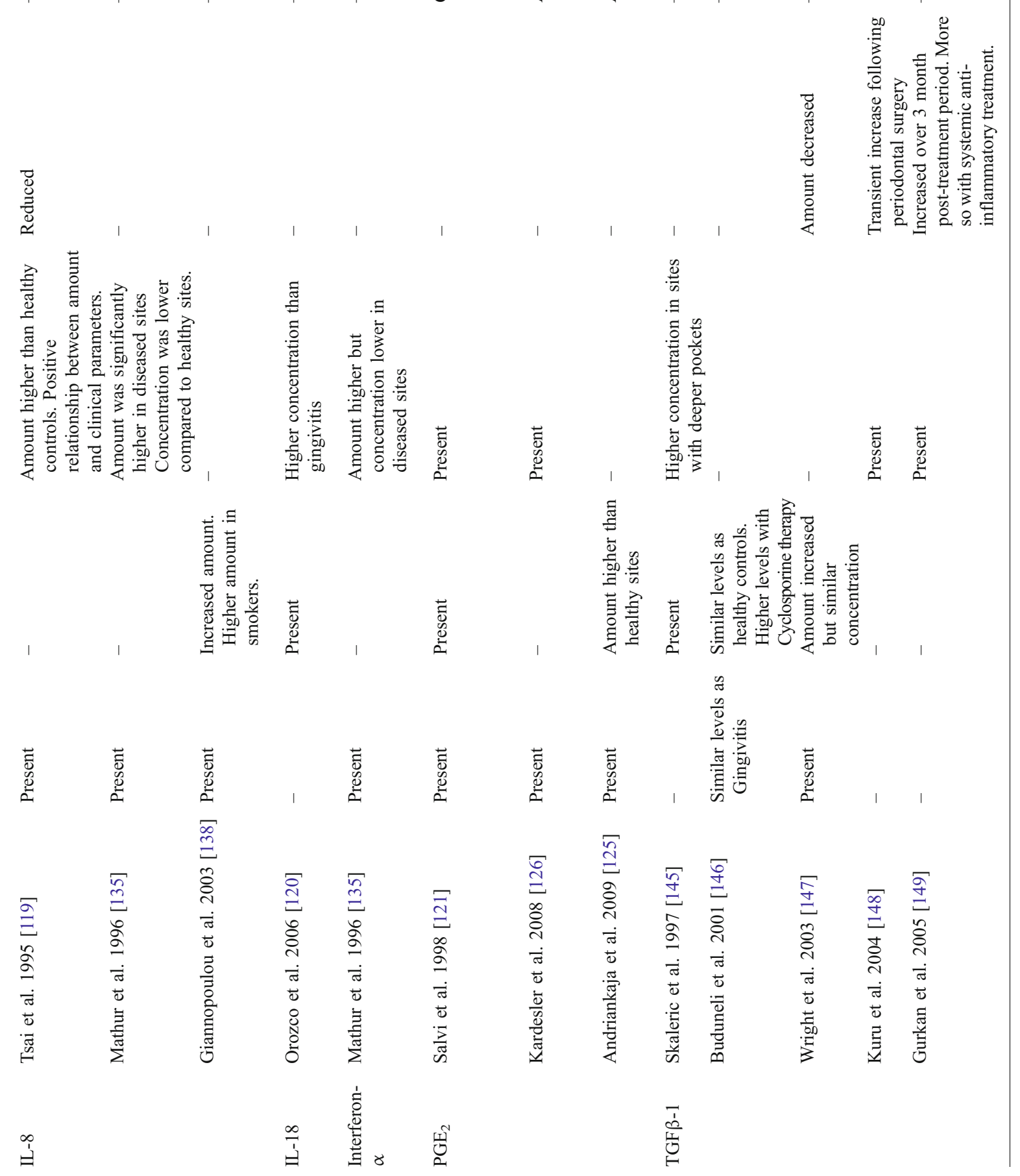
sulfate, osteonectin and bone sialoproteins [102], and on regulators of tissue destruction such as collagenase and matrix metalloproteinases including matrix metalloproteinase8 [101]. High levels of collagenase activity in GCF are associated with degradation of periodontal tissues in destructive periodontitis. In this regard, Safkan-Seppälä [115] evaluated GCF collagenase activity in poorly controlled and well-controlled diabetics and healthy controls and found that diabetic subjects had higher GCF collagenase activity than healthy controls and that the collagenase activity was related to the level of metabolic control. GCF levels of lysosomal enzymes such as beta-glucuronidase and elastase, and cytoplasmic enzymes such as lactate dehydrogenase have also been studied for their potential as a biomarker of periodontal destruction. Lamster et al. [99] reported a clinical study wherein GCF levels of beta-glucuronidase, but not lactate dehydrogenase were predictive of periodontal breakdown. Palcanis et al. [100] showed that GCF levels of elastase were significantly higher at sites which demonstrated periodontal bone loss in subsequent examinations over a six month period. More recently, Gursoy et al. [116] investigated the periodontal status and aspartate aminotransferase and lactate dehydrogenase enzyme activities in GCF of type 2 diabetic and/or obese chronic periodontitis patients, comparing these to healthy controls. Although the periodontal status was worse in subjects with diabetes, no significant differences in aspartate aminotransferase and lactate dehydrogenase enzyme activities were observed. Although the search continues for an appropriate biomarker in the GCF associated with periodontal disease presence and progression, most of the current research is focused on studies of various immuno-inflammatory proteins including cytokines, inflammatory mediators and growth factors.

Inflammatory mediators in GCF

GCF levels of IL-1 $\beta$ are known to be high in subjects with periodontitis [117-120], and even more so in subjects with diabetes [121-125]. Salvi et al. [121] compared the GCF levels of IL-1 $\beta, \mathrm{PGE}_{2}$ and TNF- $\alpha$ in diabetics and systemically healthy subjects with varying degrees of periodontal disease severity and found that diabetics had significantly higher GCF levels of both $\mathrm{PGE}_{2}$ and IL-1 $\beta$ when compared to non-diabetic controls with similar periodontal status. In addition GCF levels of IL- $1 \beta$ and $\mathrm{PGE}_{2}$ increased in diabetics as the severity of periodontal disease increased. Engebretson et al. [123] investigated the effects of glycemic control on GCF levels of IL-1 $\beta$ in patients with chronic periodontitis and type 2 diabetes and found that clinical periodontal measures and measures of glycemic control (HbAlc, random glucose) were significantly correlated with GCF IL- $1 \beta$. Patients with greater than $8 \% \mathrm{HbA} 1 \mathrm{c}$ had significantly higher mean GCF IL-1 $\beta$ 
levels than patients with less than $8 \% \mathrm{HbA} 1 \mathrm{c}$. Andriankaja et al. [125] compared the levels of serum IL-6 and GCF IL-1 $\beta$ and $\mathrm{PGE}_{2}$ in subjects with gingivitis and type 2 diabetes. GCF IL-1 $\beta$ was significantly elevated in the diabetic compared to the non-diabetic group but serum IL-6

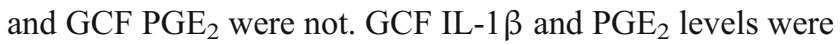
significantly elevated in subjects with gingivitis compared to subjects with gingival health regardless of diabetic status. However, serum IL-6 was elevated in subjects with gingivitis compared to healthy subjects only among those subjects with diabetes. Kardeșler et al. [126] investigated the relationship of periodontal disease in type 2 diabetics with GCF levels of PGE $_{2}$ and IL-1 $\beta$ and in contrast to most studies, found lower IL-1 $\beta$ levels in the type 2 diabetic group, and similar levels of $\mathrm{PGE}_{2}$ in diabetic and non-diabetic periodontitis patients. In general most studies report elevated levels of IL-1 $\beta$ in GCF from diabetic patients and increased expression of IL- $1 \beta$ as the severity of periodontal inflammation increases which is consistent with the hypothesis that hyperglycemia contributes to an heightened inflammatory response, and suggests a mechanism to account for the association between poor glycemic control and periodontal destruction (Table 1).

Hyperglycemia-induced activation of the protein kinase C pathway leads to increased expression of vascular endothelial growth factor (VEGF) which can alter vascular permeability and angiogenesis. The increased concentration of VEGF in periodontitis [127, 128] may be one of the reasons for the increased vascularization and permeability associated with periodontitis, and it may be regarded as a marker for disease severity. Prapulla et al. [128] compared GCF VEGF levels in gingivitis and periodontitis patients and healthy controls and found that VEGF levels in GCF increased from health to periodontitis, and that periodontal treatment resulted in a reduction of GCF VEGF levels. The authors suggested that VEGF could be considered a biomarker of periodontal disease progression. Sakallioğlu et al. [129] studied gingival tissue and GCF VEGF levels in diabetic periodontitis patients with good metabolic control compared to that of systemically healthy patients with periodontitis. This study found significantly higher VEGF levels in the gingival tissue supernatants of the diabetic group, but GCF VEGF levels were similar between the controlled diabetic and the systemically healthy subjects.

Prostaglandin $\mathrm{E}_{2}\left(\mathrm{PGE}_{2}\right)$ is associated with periodontal disease progression and alveolar bone resorption [130]. Levels of GCF $\mathrm{PGE}_{2}$ are elevated in the presence of periodontitis and perhaps even more so in diabetic patients [121]. Offenbacher et al. [131] reported significant increases in GCF PGE 2 levels a few months prior to clinically evident progression of periodontal attachment loss and suggested that monitoring of GCF $\mathrm{PGE}_{2}$ levels could be of value in predicting episodes of periodontal disease progression enabling the administration of preventive therapy before the onset of tissue destruction. More recent studies of GCF $\mathrm{PGE}_{2}$ levels in diabetic patients have, however cast some doubt on the usefulness of this agent as biomarker of disease progression. Kardesler et al. [126] observed that GCF $\mathrm{PGE}_{2}$ levels in diabetics were higher than healthy controls when levels were expressed as total amount of $\mathrm{PGE}_{2}$. When GCF $\mathrm{PGE}_{2}$ levels were expressed as concentration of $\mathrm{PGE}_{2}$ the concentration of $\mathrm{PGE}_{2}$ was lower in GCF from diabetic subjects. These findings suggest that the differences in GCF $\mathrm{PGE}_{2}$ levels are more a function of increased volume of GCF in the diabetic rather than an increased expression of $\mathrm{PGE}_{2}$. Andriankaja et al. [125] compared GCF $\mathrm{PGE}_{2}$ levels in diabetics and healthy controls during the development of experimental gingivitis, and found that GCF $\mathrm{PGE}_{2}$ levels increased with the presence of gingivitis, but that the amount of GCF $\mathrm{PGE}_{2}$ was similar in diabetics and healthy controls (Table 1).

Hyperglycemia-induced activation of the protein kinase $C$ pathway also results in increased expression of transforming growth factor (TGF)- $\beta$ which leads to changes in collagen and fibronectin thereby promoting capillary occlusion. Gurkan et al. [132] measured GCF TGF- $\beta 1$ in several forms of periodontal disease and found that GCF levels of TGF- $\beta 1$ were significantly elevated in subjects with periodontitis compared to healthy controls and that GCF TGF- $\beta 1$ levels were correlated with all clinical periodontal parameters. Schierano et al. [133] measured TNF- $\alpha$, TGF- $\beta 2$ and IL-1 $\beta$ levels in GCF before and after the onset of experimental gingivitis in non-diabetic subjects. Although the volume of the crevicular fluid and the GCF levels of IL$1 \beta$ increased significantly with the onset of gingivitis, TNF- $\alpha$ and TGF- $\beta 2$ levels in GCF did not change significantly. GCF expression of transforming growth factor in diabetic periodontitis patients has not been reported (Table 1).

Other inflammatory mediators which have been studied as potential biomarkers of periodontal disease include IL$1 \alpha$, IL-6, IL-8, IL-18, Interferon- $\alpha$, and TNF- $\alpha$ (Table 1). GCF levels of IL- $1 \alpha$ have been shown to be increased in the presence of gingivitis and periodontitis [134-136] and to decrease following periodontal treatment $[134,136]$. No studies of GCF levels of IL- $1 \alpha$ in diabetic subjects have been reported. Kurtis et al. [137] compared GCF levels of IL-6 in diabetics and healthy controls with and without periodontitis. The concentration of IL-6 in GCF was higher in periodontitis than in healthy gingival sulci, and was higher in diabetic patients than that of both healthy controls and non-diabetic patients with periodontitis. GCF levels of IL-8 [119, 135, 138], IL-18 [120] and Interferon- $\alpha$ [135] have also been shown to increase in the presence of gingivitis and periodontitis. In addition the GCF levels of IL-8 have been shown to decrease following periodontal treatment [119]. However, no studies of GCF levels of IL-8, 
IL-18 or Interferon- $\alpha$ in diabetics have been reported (Table 1).

Studies have also investigated the potential of various components of saliva for diagnosing and evaluating the prognosis and evolution of diabetes mellitus and its oral manifestations. Borg Andersson et al. [139] studied the glucose content of parotid saliva and found that salivary levels of glucose peaked at two hours following a glucose challenge and was significantly elevated in subjects with impaired glucose tolerance or diabetes mellitus, but not in healthy controls. Arana et al. [140] compared markers of oxidative stress in saliva from patients with type 2 diabetes mellitus with that of healthy controls and found significantly higher glutathione peroxidase and glutathione reductase activity, and significantly lower reduced glutathione in diabetic subjects. More recently Gumus et al. [141] also reported significantly lower reduced glutathione in diabetic subjects, but only in type 1 diabetics, and no other differences in the levels of other salivary antioxidants were observed. Possible explanations for the differences in the findings of these studies may include the fact that stimulated saliva samples were employed in one study [140], while unstimulated samples were evaluated in the other [141]. In addition, the prevalence and severity of periodontal disease differed somewhat between the two studies, as well as the methods used to diagnose and describe the degree of periodontal involvement.

\section{Conclusion}

In view of the fact that diabetes mellitus and periodontitis share many features consistent with chronic inflammatory disorders, it is reasonable to pursue the identification and utility of biomarkers of disease status that are common to these diseases, and that can be used to evaluate a patient's disease status and better design intervention strategies. Studies in diabetic patients have indicated that the ex vivo quantification of gelatinase activity in serum and the expression of recoverin in mononuclear blood cells were useful for the prediction of active proliferative retinopathy, suggesting that diabetic patients might be monitored for the expressions of these molecules for more effective timing of appropriate therapy [150]. Studies conducted to date suggest that gingival crevicular fluid may be an acceptable substitute for "finger stick" blood for determination of serum glucose levels and may therefore be a useful screening tool in the dental office. Although considerable effort has been applied in the attempt to identify an immuno-inflammatory biomarker for these diseases, the ideal biomarker has yet to be found. Some of the promising inflammatory cytokines and growth factors that are expressed in the GCF as a part of the host response and that have been shown to be elevated in both periodontitis and diabetes include IL-1 $\beta$, IL-6, PGE 2 , and VEGF. However, none of these agents have been shown to be a valid biomarker due to inconclusive, conflicting or insufficient data. Although we have known for some time that the presence of these cytokines are increased in the GCF during infection and inflammation, it has been hard to quantify this association in terms of determining the extent to which the quantity of the expressed cytokine goes up or down with changes in inflammation. Further research is necessary to clarify the usefulness of these potential biomarkers and to likewise investigate additional cytokines which have yet to be studied in this regard.

\section{References}

1. Biomarkers Definitions Working Group. Biomarkers and surrogate endpoints: preferred definitions and conceptual framework. Clin Pharmacol Ther. 2001;69:89-95.

2. Mealey B, Rees T, Rose L. Systemic factors impacting the periodontium. In: Rose L, Mealey B, editors. Periodontics medicine, surgery, and implants. St. Louis: Elsevier Mosby; 2004.

3. Loe H. Periodontal disease: The sixth complication of diabetes mellitus. Diabetes Care. 1993;16 Suppl 1:329-34.

4. Mealey B, Oates T. Diabetes mellitus and periodontal diseases. J Periodontol. 2006;77:1289-303.

5. Papapanou P. Periodontal diseases: epidemiology. Ann Periodontol. 1996;1:1-36.

6. Bacic M, Plancak D, Granic M. CPITN assessment of periodontal status in diabetic patients. J Periodontol. 1988;59: 816-22.

7. Emrich L, Shlossman M, Genco R. Periodontal disease in noninsulin dependent diabetes mellitus. J Periodontol. 1991;62:123-31.

8. Shlossman M, Knowler W, Pettitt D, et al. Type 2 diabetes mellitus and periodontal disease. J Am Dent Assoc. 1990;121: $532-6$.

9. Tervonen T, Oliver R. Long-term control of diabetes mellitus and periodontitis. J Clin Periodontol. 1993;20:431-5.

10. Gusberti F, Syed S, Bacon G, et al. Puberty gingivitis in insulindependent diabetic children. I. Cross-sectional observations. J Periodontol. 1983;54:714-20.

11. Sastrowijoto $\mathrm{S}$, van der Velden $\mathrm{U}$, van Steenbergen $\mathrm{T}$, et al. Improved metabolic control, clinical periodontal status, and subgingival microbiology in insulin-dependent diabetes mellitus. A prospective study. J Clin Periodontol. 1990;17:233-42.

12. Karjalainen K, Knuuttila M. The onset of diabetes and poor metabolic control increases gingival bleeding in children and adolescents with insulin-dependent diabetes mellitus. J Clin Periodontol. 1996;23:1060-7.

13. Ervasti T, Knuuttila M, Pohjamo L, et al. Relation between control of diabetes and gingival bleeding. J Periodontol. 1985;56:154-7.

14. Cutler C, Machen R, Jotwani R, et al. Heightened gingival inflammation and attachment loss in type 2 diabetics with hyperlipidemia. J Periodontol. 1999;70:1313-21.

15. Lalla E, Park D, Papapanou P, et al. Oral disease burden in Northern Manhattan patients with diabetes mellitus. Am J Public Health. 2004;94:755-8.

16. Lalla E, Cheng B, Lal S, et al. Diabetes-related parameters and periodontal conditions in children. J Periodontal Res. 2007;42: 345-9. 
17. Tervonen T, Oliver R. Long-term control of diabetes mellitus and periodontitis. J Clin Periodontol. 1993;20:431-5.

18. Guzman S, Karima M, Wang H-Y, et al. Association between interleukin-1 genotype and periodontal disease in a diabetic population. J Periodontol. 2003;74:1183-90.

19. Taylor G, Burt B, Becker M, et al. Non-insulin dependent diabetes mellitus and alveolar bone loss progression over 2 years. J Periodontol. 1998;69:76-83.

20. Westfelt E, Rylander H, Blohmé G, et al. The effect of periodontal therapy in diabetics. Results after 5 years. J Clin Periodontol. 1996;23:92-100.

21. Karjalainen K, Knuuttila M, von Dickhoff K. Association of the severity of periodontal disease with organ complications in type 1 diabetic patients. J Periodontol. 1994;65:1067-72.

22. Tervonen T, Karjalainen K. Periodontal disease related to diabetic status. A pilot study of the response to periodontal therapy in type 1 diabetes. J Clin Periodontol. 1997;24:505-10.

23. Ryder M. Anatomy, development, and physiology of the periodontium. In: Rose L, Mealey B, editors. Periodontics medicine, surgery, and implants. St. Louis: Elsevier Mosby; 2004.

24. Grant D, Stern B, Everett F. Orban's periodontics: a concepttheory and practice. Saint Louis: Mosby; 1972.

25. Page R, Offenbacher S, Schroeder H, et al. Advances in the pathogenesis of periodontitis. Summary of developments, clinical implications and future directions. Periodontol 2000. 1997;14: 12-32.

26. Page R, Schroeder H. Pathogenesis of inflammatory periodontal disease. A summary of current work. Lab Invest. 1976;34:235-49.

27. Oliver R, Brown L, Loe H. Periodontal diseases in the United States population. J Periodontol. 1998;69:269-78.

28. Lindhe J, Okamoto H, Yoneyama T, et al. Longitudinal changes in periodontal disease in untreated subjects. J Clin Periodontol. 1989;16:662-70.

29. Kornman K. Patients are not equally susceptible to periodontitis. Does this change dental practice and dental curriculum? J Dent Educ. 2001;65:777-84.

30. Machtei E, Hausmann E, Dunford R, et al. Longitudinal study of predictive factors for periodontal disease and tooth loss. J Clin Periodontol. 1999;26:374-80.

31. Burt B. American Academy of Periodontology Position paper: epidemiology of periodontal diseases. J Periodontol. 2005;76:1406-19.

32. Lang N, Tonetti M, Suter J, et al. Effect of interleukin-1 gene polymorphisms on gingival inflammation assessed by bleeding on probing in a periodontal maintenance population. J Periodont Res. 2000;35:102-7.

33. Muller H, Stadermann S, Heinecke A. Longitudinal association between plaque and gingival bleeding in smokers and nonsmokers. J Clin Periodontol. 2002;29:287-94.

34. Deinzer R, Forster P, Fuck L, et al. Increase of crevicular interleukin 1-beta under academic stress at experimental gingivitis sites and at sites of perfect oral hygiene. J Clin Periodontol. 1999;26:1-8.

35. Baelum V. Pattern of periodontal breakdown in adult Tanzanians. Scand J Dent Res. 1987;95:221-8.

36. Baelum V, Fejerskov O, Manji F. Periodontal diseases in adult Kenyans. J Clin Periodontol. 1988;15:445-52.

37. Emrich L, Shlossman M, Genco RJ. Periodontal disease in non-insulin-dependent diabetes mellitus. J Periodontol. 1991;62: 123-30.

38. Guzman S, Karima M, Wang H-Y, et al. Association between interleukin-1 genotype and periodontal disease in a diabetic population. J Periodontol. 2003;74:1183-90.

39. Tervonen T, Knuuttila M. Relation of diabetes control to periodontal pocketing and alveolar bone level. Oral Surg Oral Med Oral Pathol. 1986;61:346-9.
40. Safkan-Seppala B, Ainamo J. Periodontal conditions in insulindependent diabetes mellitus. J Clin Periodontol. 1992;19:24-9.

41. Seppala B, Seppala M, Ainamo J. A longitudinal study on insulin-dependent diabetes mellitus and periodontal disease. J Clin Periodontol. 1993;20:161-5.

42. Seppala B, Ainamo J. A site-by-site follow-up study on the effect of controlled versus poorly controlled insulin-dependent diabetes mellitus. J Clin Periodontol. 1994;21:161-5.

43. Tsai C, Hayes C, Taylor G. Glycemic control of type 2 diabetes and severe periodontal disease in the U.S. adult population. Community Dent Oral Epidemiol. 2002;30:182-92.

44. Taylor G, Burt B, Becker M, et al. Glycemic control and alveolar bone loss progression in type 2 diabetes. Ann Periodontol. 1998;3:30-9.

45. Sastrowijoto S, Hillemans $P$, Van Steenbergen $T$, et al. Periodontal condition and microbiology of healthy and diseased periodontal pockets in type 1 diabetes mellitus patients. J Clin Periodontol. 1989;16:316-22.

46. Zambon J, Reynolds H, Fisher J, et al. Microbiological and immunological studies of adult periodontitis in patients with non-insulin dependent diabetes mellitus. J Periodontol. 1988;59: 23-31.

47. Sbordone L, Ramaglia L, Barone A, et al. Periodontal status and subgingival microbiota of insulin-dependent juvenile diabetics: a 3-year longitudinal study. J Periodontol. 1998;69:120-8.

48. Manouchehr-Pour M, Spagnuolo P, Rodman H, et al. Comparison of neutrophil chemotactic response in diabetic patients with mild and severe periodontal disease. J Periodontol. 1981;52:410-5.

49. McMullen J, Van Dyke T, Horoszewicz H, et al. Neutrophil chemotaxis in individuals with advanced periodontal disease and a genetic predisposition to diabetes mellitus. J Periodontol. 1981;52:167-73.

50. Schmidt A, Yan S, Wautier J-L, et al. Activation of receptor for advanced glycation end products. A mechanism for chronic vascular dysfunction in diabetic vasculopathy and atherosclerosis. Circ Res. 1999;84:489-97.

51. Schmidt A, Hori O, Cao R, et al. RAGE: a novel cellular receptor for advanced glycation end products. Diabetes. 1996;45 Suppl 3:S77-80.

52. Loder R. The influence of diabetes mellitus on the healing of closed fractures. Clin Orthop. 1988;232:210-6.

53. Inaba M, Nishizawa Y, Mita K, et al. Poor glycemic control impairs the response of biochemical parameters of bone formation and resorption to exogenous 1,25-dihydroxyvitamin D3 in patients with type 2 diabetes. Osteoporos Int. 1999;9:525-31.

54. Tisdel C, Marcus R, Heiple K. Triple arthrodesis for diabetic peritalar neuroarthropathy. Foot Ankle Int. 1995;16:332-8.

55. White C, Turner N, Lee G, et al. Open ankle fractures in patients with diabetes mellitus. Clin Orthop. 2003;414:37-44.

56. Beam H, Parsons J, Lin S. The effects of blood glucose control upon fracture healing in the BB Wistar rat with diabetes mellitus. J Orthop Res. 2002;20:1210-6.

57. Gooch H, Hale J, Fujioka H, et al. Alterations of cartilage and collagen expression during fracture healing in experimental diabetes. Connect Tissue Res. 2000;41:81-5.

58. Lu H, Kraut D, Gerstenfeld L, et al. Diabetes interferes with bone formation by affecting the expression of transcription factors that regulate osteoblast differentiation. Endocrinology. 2003; 144:346-52.

59. He H, Liu R, Desta $T$, et al. Diabetes causes decreased osteoclastogenesis, reduced bone formation, and enhanced apoptosis of osteoblastic cells in bacteria stimulated bone loss. Endocrinology. 2004;145:447-52.

60. Liu R, Desta T, He H, et al. Diabetes alters the response to bacteria by enhancing fibroblast apoptosis. Endocrinology. 2004;145:2997-3003. 
61. Liu R, Bal H, Desta T, et al. Diabetes enhances periodontal bone loss through enhanced resorption and diminished bone formation. J Dent Res. 2006;85:510-4.

62. Nishimura F, Takahashi K, Kurihara M, et al. Periodontal disease as a complication of diabetes mellitus. Ann Periodontol. 1998;3: 20-9.

63. Schmidt A, Weidman E, Lalla E, et al. Advanced glycation end products (AGEs) induce oxidant stress in the gingiva: a potential mechanism underlying accelerated periodontal disease associated with diabetes. J Periodontol Res. 1996;31:508-15.

64. Paques M, Massin P, Gaudric A. Growth factors and diabetic retinopathy. Diabetes Metab. 1997;23:125-30.

65. Chiarelli F, Santilli F, Mohn A. Role of growth factors in the development of diabetic complications. Horm Res. 2000;53:53-67.

66. Unlu F, Gurdal Guneri P, Hekimgil M, et al. Expression of vascular endothelial growth factor in human periodontal tissues: comparison of healthy and diabetic patients. J Periodontol. 2003;74:181-7.

67. Taylor G, Burt B, Becker M, et al. Severe periodontitis and risk for poor glycemic control in patients with non-insulin-dependent diabetes mellitus. J Periodontol. 1996;67(10 Suppl):1085-93.

68. Grossi S, Genco R. Periodontal disease and diabetes mellitus: a two-way relationship. Ann Periodontol. 1998;3:51-61.

69. Taylor G, Burt B, Becker M, et al. Non-insulin dependent diabetes mellitus and alveolar bone loss progression over 2 years. J Periodontol. 1998;69:76-83.

70. Lalla E, Lamster I, Drury S, et al. Hyperglycemia, glycoxidation and receptor for advanced glycation end products: potential mechanisms underlying diabetic complications, including diabetesassociated periodontitis. Periodontol 2000. 2000;23:50-62.

71. Soskolne W, Klinger A. The relationship between periodontal diseases and diabetes: an overview. Ann Periodontol. 2001;6: 91-8.

72. Taylor G. Bidirectional interrelationships between diabetes and periodontal diseases: an epidemiologic perspective. Ann Periodontol. 2001;6(1):99-112.

73. Grossi S, Skrepcinski F, DeCaro T, et al. Treatment of periodontal disease in diabetics reduces glycated hemoglobin. J Periodontol. 1997;68:713-9.

74. Kiran M, Arpak N, Unsal E, et al. The effect of improved periodontal health on metabolic control in type 2 diabetes mellitus. J Clin Periodontol. 2005;32:266-72.

75. Faria-Almeida R, Navarro A, Bascones A. Clinical and metabolic changes after conventional treatment of type 2 diabetic patients with chronic periodontitis. J Periodontol. 2006;77:591-8.

76. Stewart J, Wager K, Friedlander A, et al. The effect of periodontal treatment on glycemic control in patients with type 2 diabetes mellitus. Clin Periodontol. 2001;28:306-10.

77. Page R, Offenbacher S, Schroeder H, et al. (1997) Advances in the pathogenesis of periodontitis: summary of developments, clinical implications and future directions. Periodontol. 2000;14: 216-48.

78. Salvi G, Brown C, Fujihashi K, et al. Inflammatory mediators of the terminal dentition in adult and early onset periodontitis. $\mathrm{J}$ Periodontol. 1998;33:212-25.

79. Iehara N, Takeoka H, Yamada Y, et al. Advanced glycation end products modulate transcriptional regulation in mesangial cells. Kidney Int. 1996;50:1166-72.

80. Brownlee M. The pathological implications of protein glycation. Clin Invest Med. 1995; 18:275-81.

81. Tanimoto K, Ohno S, Fujimoto K, et al. Proinflammatory cytokines regulate the gene expression of hyaluronic acid synthetase in cultural rabbit synovial membrane cells. Connect Tissue Res. 2001;42:187-96.

82. Lalla E, Lamster I, Stern D, et al. Receptor for advanced glycation end products, inflammation, and accelerated periodontal disease in diabetes: mechanisms and insights into therapeutic modalities. Ann Periodontol. 2001;6:113-8.

83. Tan K, Chow W, Tam S, et al. Association between acute-phase reactants and advanced glycation end products in type 2 diabetes. Diabetes Care. 2004;27:223-8.

84. Jambou D, Dejour N, Bayer P, et al. Effect of human native lowdensity and high-density lipoproteins on prostaglandin production by mouse macrophage cell line P338D1: possible implication in pathogenesis of atherosclerosis. Biochim Biophys Acta. 1993;1168: $115-21$.

85. Salback PB, Specht E, von Hodenberg E, et al. Differential low density lipoprotein receptor-dependent formation of eicosanoids in human blood-derived monocytes. Proc Nat Acad Sci (USA). 1992;89:2439-43.

86. Offenbacher S. Periodontal diseases: pathogenesis (review). Ann Periodontol. 1996;1:821-78.

87. Schmidt A, Hort O, Brett J, et al. Cellular receptors for advanced glycation end products. Implications for induction of oxidant stress and cellular dysfunction in the pathogenesis of vascular lesions. Arterioscler Thromb. 1994;14:1521-8.

88. Raynes J. The active phase response. Biochem Soc Trans. 1994;22:69-74.

89. Paz K, Hemi R, LeRoith D, et al. A molecular basis for insulin resistance-elevated serine/threonin phosphorylation of IRS-1 and IRS-2 inhibits their binding to the juxtamembrane region of the insulin receptor and impairs their ability to undergo insulin-induced tyrosine phosphorylation. J Biol Chem. 1997;272:29911-8.

90. Yoshimura A, Kaneko T, Kato Y, et al. Lipopolysaccharides from periodontopathic bacteria Porphyromonas gingivalis and Capnocytophaga ochracea are antagonists for human Toll-like receptor 4. Infect Immun. 2002;70:218-25.

91. Ogawa T, Asai Y, Hashimoto M, et al. Cell activation by Porphyromonas gingivalis lipid A molecule through Toll-like receptor 4- and myeloid differentiation factor 88-dependent signaling pathway. Int Immunol. 2002;14:1325-32.

92. Streja D, Cressey P, Rabkin S. Associations between inflammatory markers, traditional risk factors, and complications in patients with type 2 diabetes mellitus. J Diabetes Complications. 2003; 17:120-7.

93. Black P. The inflammatory response in an integral part of the stress response: implications for atherosclerosis, insulin resistance, type 2 diabetes and metabolic syndrome X. Behav Immun. 2003;17:350-64.

94. Soory M. Hormone mediation of immune responses in the progression of diabetes, rheumatoid arthritis and periodontal diseases. Curr Drug Targets-Immune, Endocrine Metab Disorders. 2002;2:13-25.

95. Suppipat N, Suppipat N. Evaluation of an electronic device for gingival fluid quantitation. J Periodontol. 1977;48:388-94.

96. Hinrichs J, Bandt C, Smith J, et al. A comparison of 3 systems for quantifying gingival crevicular fluid with respect to linearity and the effects of qualitative differences in fluids. J Clin Periodontol. 1984;11:652-61.

97. Williams R, Pacquette D. Advances in periodontal diagnosis. In: Lindhe J, Karring T, Lang NP, editors. Clinical periodontology and implant dentistry. 3rd ed. Copenhagen: Munksgaard; 1997.

98. Offenbacher S, Farr D, Goodson J. Measurement of prostaglandin E in crevicular fluid. J Clin Periodontol. 1981;8:359-67.

99. Lamster I, Oshrain R, Harper D, et al. Enzyme activity in crevicular fluid for detection and prediction of clinical attachment loss in patients with chronic adult periodontitis. Six month results. J Periodontol. 1988;59:516-23.

100. Palcanis K, Larjava I, Wells B, et al. Elastase as an indicator of periodontal disease progression. J Periodontol. 1992;63:237-42. 
101. Kinane D. Regulators of tissue destruction and homeostasis as diagnostic aids in periodontology. Periodontology 2000. 2000;24:215-25.

102. Embery G, Waddington R, Hall R, et al. Connective tissue elements as diagnostic aids in periodontology. Periodontology 2000. 2000;24:193-214.

103. Strauss S, Wheeler A, Russell S, et al. The potential use of gingival crevicular blood for measuring glucose to screen for diabetes: an examination based on characteristics of the blood collection site. J Periodontol. 2009;80:907-14.

104. Yamaguchi M, Kambe S, Yamazaki K, et al. Error grid analysis of noninvasive glucose monitoring via gingival crevicular fluid. IEEE Trans Biomed Eng. 2005;52:1796-8.

105. Yamaguchi M, Takada R, Kambe S, et al. Evaluation of timecourse changes of gingival crevicular fluid glucose levels in diabetics. Biomed Microdevices. 2005;7:53-8.

106. Yamaguchi M, Kawabata Y, Kambe S, et al. Non-invasive monitoring of gingival crevicular fluid for estimation of blood glucose level. Med Biol Eng Comput. 2004;42:322-7.

107. Khader Y, Al-Zubi B, Judeh A, et al. Screening for type 2 diabetes mellitus using gingival crevicular blood. Int $\mathrm{J}$ Dent Hygiene. 2006;4:179-82.

108. Beikler T, Kuczek A, Petersilka G, et al. In-dental-office screening for diabetes mellitus using gingival crevicular blood. J Clin Periodontol. 2002;29:216-8.

109. Müller H, Behbehani E. Screening of elevated glucose levels in gingival crevice blood using a novel, sensitive self-monitoring device. Med Princ Pract. 2004;13:361-5.

110. Müller H, Behbehani E. Methods for measuring agreement: glucose levels in gingival crevice blood. Clin Oral Investig. 2005;9:65-9.

111. Ardakani M, Moeintaghavi A, Haerian A, et al. Correlation between levels of sulcular and capillary blood glucose. J Contemp Dent Pract. 2009;10:10-7.

112. Ficara A, Levin M, Grower M, et al. A comparison of the glucose and protein content of gingival crevicular fluid from diabetics and nondiabetics. J Periodont Res. 1975;10:171-5.

113. Parker R, Rapley J, Isley W, et al. Gingival crevicular blood for assessment of blood glucose in diabetic patients. J Periodontol. 1993;64(7):666-72.

114. Ciantar M, Spratt D, Newman H, et al. Development of an in vitro microassay for glucose quantification in submicrolitre volumes of biological fluid. J Periodont Res. 2002;37:79-85.

115. Safkan-Seppälä B, Sorsa T, Tervahartiala T, et al. Collagenases in gingival crevicular fluid in type 1 diabetes mellitus. J Periodontol. 2006;77:189-94.

116. Gursoy U, Marakoglu I, Ersan S. Periodontal status and cytoplasmic enzyme activities in gingival crevicular fluid of type 2 diabetic and/or obese patients with chronic periodontitis. J Int Acad Periodontol. 2006;8:2-5.

117. Engebretson S, Hey-Hadavi J, Ehrhardt F, et al. Gingival crevicular fluid levels of interleukin- $1 \beta$ and glycemic control in patients with chronic periodontitis and type 2 diabetes. J Periodontol. 2004;75:1203-8.

118. Hou L, Liu C, Rossomando E. Crevicular interleukin-1 beta in moderate and severe periodontitis patients and the effect of phase I periodontal treatment. J Clin Periodontol. 1995;22:162-7.

119. Tsai C, Ho Y, Chen C. Levels of interleukin-1 beta and interleukin-8 in gingival crevicular fluids in adult periodontitis. J Periodontol. 1995;66:852-9.

120. Orozco A, Gemmell E, Bickel $\mathrm{M}$, et al. Interleukin-1beta, interleukin-12 and interleukin-18 levels in gingival fluid and serum of patients with gingivitis and periodontitis. Oral Microbiol Immunol. 2006;21:256-60.

121. Salvi G, Beck J, Offenbacher S. PGE 2 , IL-1 $\beta$, and TNF- $\alpha$ responses in diabetics as modifiers of periodontal disease expression. Ann Periodontol. 1998;3:40-50.
122. Bulut U, Develioglu H, Taner IL, et al. Interleukin-1 beta levels in gingival crevicular fluid in type 2 diabetes mellitus and adult periodontitis. J Oral Sci. 2001;43:171-7.

123. Engebretson S, Grbic J, Singer R, et al. GCF IL-1b profiles in periodontal disease. J Clin Periodontol. 2002;29:48-53.

124. Zhong Y, Slade G, Beck J, et al. Gingival crevicular fluid interleukin-1beta, prostaglandin $\mathrm{E}_{2}$ and periodontal status in a community population. J Clin Periodontol. 2007;34: 285-93.

125. Andriankaja O, Barros S, Moss $\mathrm{K}$, et al. Levels of serum interleukin (IL)-6 and gingival crevicular fluid of IL-1 $\beta$ and prostaglandin $\mathrm{E}_{2}$ among non-smoking subjects with gingivitis and type 2 diabetes. J Periodontol. 2009;80:307-16.

126. Kardeșler L, Buduneli N, Biyikoğlu B, et al. Gingival crevicular fluid $\mathrm{PGE}_{2}$, IL-1 $\beta$, t-PA, PAI-2 levels in type 2 diabetes and relationship with periodontal disease. Clin Biochem. 2008;41: 863-8.

127. Güneri P, Ünlü F, Yeșilbek B, et al. Vascular endothelial growth factor in gingival tissues and crevicular fluids of diabetic and healthy periodontal patients. J Periodontol. 2004;75:91-7.

128. Prapulla D, Sujatha P, Pradeep A. Gingival Crevicular Fluid VEGF Levels in Periodontal Health and Disease. J Periodontol. 2007;78:1783-7.

129. Sakallioğlu E, Aliyev E, Lütfioğlu M, et al. Vascular endothelial growth factor (VEGF) levels of gingiva and gingival crevicular fluid in diabetic and systemically healthy periodontitis patients. Clin Oral Investig. 2007;11:115-20.

130. Heasman P, Collins J, Offenbacher S. Changes in crevicular fluid levels of interleukin-1, beta leukotriene B4, prostaglandin E2, thromboxane B2 and tumour necrosis factor alpha in experimental gingivitis in humans. J Periodontal Res. 1993;28:241-7.

131. Offenbacher S, Odle B, Van Dyke T. The use of crevicular fluid prostaglandin E2 levels as a predictor of periodontal attachment loss. J Periodontal Res. 1986;21:101-12.

132. Gurkan A, Emingil G, Cinarcık S, et al. Gingival crevicular fluid transforming growth factor- $\beta 1$ in several forms of periodontal disease. Arch Oral Biol. 2006;51:906-12.

133. Schierano G, Pejrone G, Brusco P, et al. TNF- $\alpha$, TGF- $\beta 2$ and IL-1 $\beta$ levels in gingival and peri-implant crevicular fluid before and after de novo plaque accumulation. J Clin Periodontol. 2008;35:532-8.

134. Masada M, Persson R, Kenny J, et al. Measurement of interleukin-1 alpha and -1 beta in gingival crevicular fluid: implications for the pathogenesis of periodontal disease. J Periodont Res. 1990;25:156-63.

135. Mathur A, Michalowicz B, Castillo M, et al. Interleukin-1 alpha, interleukin-8 and interferon-alpha levels in gingival crevicular fluid. J Periodontal Res. 1996;31:489-95.

136. Tsalikis L, Parapanisiou E, Bata-Kyrkou A, et al. Crevicular fluid levels of interleukin-1alpha and interleukin-1beta during experimental gingivitis in young and old adults. J Int Acad Periodontol. 2002;4:5-11.

137. Kurtis B, Develioğlu H, Taner I, et al. IL-6 levels in gingival crevicular fluid (GCF) from patients with non-insulin dependent diabetes mellitus (NIDDM), adult periodontitis and healthy subjects. J Oral Sci. 1999;41:163-7.

138. Giannopoulou C, Bernard J, Buser D, et al. Effect of intracrevicular restoration margins on peri-implant health: clinical, biochemical, and microbiologic findings around esthetic implants up to 9 years. Int J Oral Maxillofac Implants. 2003; 18:173-81.

139. Borg Andersson A, Birkhed D, Berntorp K, et al. Glucose concentration in parotid saliva after glucose/food intake in individuals with glucose intolerance and diabetes mellitus. Eur J Oral Sci. 1998;106:931-7. 
140. Arana C, Cutando A, Ferrera M, et al. Parameters of oxidative stress in saliva from diabetic and parenteral drug addict patients. J Oral Pathol Med. 2006;35:554-9.

141. Gumus P, Buduneli N, Cetinkalp S, et al. Salivary antioxidants in patients with type 1 or type 2 diabetes and inflammatory periodontal disease: a case-control study. J Periodontol. 2009;80:1440-6.

142. Figueredo C, Ribeiro M, Fischer R, et al. Increased interleukin$1 \beta$ concentration in gingival crevicular fluid as a characteristic of periodontitis. J Periodontol. 1999;70:1457-63.

143. Gonzales J, Herrmann J, Boedeker R, et al. Concentration of interleukin-1 $\beta$ and neutrophil elastase activity in gingival crevicular fluid during experimental gingivitis. J Clin Periodontol. 2001;28:544-9.

144. Faizuddin M, Bharathi S, Rohini N. Estimation of interleukin- $1 \beta$ levels in the gingival crevicular fluid in health and in inflammatory periodontal disease. J Periodont Res. 2003;38:111-4.

145. Skateric U, Kramar B, Petelin M, et al. Changes inTGF $\beta 1$ levels in gingiva, crevicular fluid and serum associated with periodontal inflammation in humans and dogs. Eur J Oral Sci. 1997;105:13642.

146. Buduneli N, Kutukculer N, Aksu G, et al. Evaluation of transforming growth factor $-\beta 1$ level in crevicular fluid of cyslosporin A-treated patients. J Periodontol. 2001;72:526-31.

147. Wright H, Chapple I, Matthews J. Levels of TGF $\beta 1$ in gingival crevicular fluid during a 21-day experimental model of gingivitis. Oral Dis. 2003;9:88-94.

148. Kuru L, Griffiths G, Petrie A, et al. Changes in transforming growth factor- $\beta 1$ in gingival crevicular fluid following periodontal surgery. J Clin Periodontol. 2004;31:527-33.

149. Gurkan A, Cinarcik S, Huseyinov A. Adjunctive subantimicrobial dose doxycycline:effect on clinical parameters and gingival crevicular fluid transforming growth factor bllevels in severe, generalized chronic periodontitis. J Clin Periodontol. 2005;32:244 53 .

150. Golubnitschaja O, Jaksche A, Moenkemann H, et al. Molecular imaging system for possible prediction of active retinopathy in patients with diabetes mellitus. Amino Acids. 2005;28:229-37. 